\title{
MSW management strategies for the city of Rome: a comparative assessment
}

\section{Francesco Lombardi, Giulia Costa* and Renato Gavasci}

Civil Engineering Department,

University of Rome 'Tor Vergata',

Rome, Italy

Email: lombardi@ing.uniroma2.it

Email: costa@ing.uniroma2.it

Email: gavasci@ing.uniroma2.it

*Corresponding author

\section{Paola Muraro}

Largo Tenente Bellini 1, 00197 Rome, Italy

Email: muraro-p@libero.it

\begin{abstract}
In this paper, on the basis of a detailed characterisation of the Municipal Solid Waste (MSW) generated in the city of Rome, different integrated management strategies regarding both source separation of selected fractions and the treatment and disposal of the residual commingled waste were compared and discussed in terms of achievable material and energy recovery. The main findings of this study, that can be extended to other regions characterised by similar environmental policies and social and economical conditions, showed that source separation percentages cannot realistically exceed certain maximum percentages, particularly when they are addressed at selecting waste fractions for recycling. Regarding the management of the residual commingled waste, thermal treatment of all the fractions for which no further material recovery can be realistically pursued resulted the most convenient strategy in terms of recoverable thermal energy.
\end{abstract}

Keywords: composition; energy recovery; material recovery; integrated management strategies; MBT; mechanical biological treatment; MSW; municipal solid waste; recycling; RDF; refuse derived fuel; residual commingled waste; source separation.

Reference to this paper should be made as follows: Lombardi, F., Costa, G., Gavasci, R. and Muraro, P. (2010) 'MSW management strategies for the city of Rome: a comparative assessment', Int. J. Environmental Technology and Management, Vol. 13, Nos. 3/4, pp. 281-301.

Biographical notes: Francesco Lombardi is Associate Professor in Sanitary and Environmental Engineering at the University of Rome 'Tor Vergata', Italy. He received a Master's degree in Hydraulic Engineering from the University of Rome 'La Sapienza' and a Doctorate in Sanitary and Environmental Engineering from the Polytechnic of Milan. From 1995 to 1998, he was plant manager of the hospital waste incineration plant of Rome. His main research activities regard waste incineration and hazardous waste treatment. He has co-authored several international scientific publications on solid waste incineration, flue gas treatment and the leaching and mechanical behaviour of stabilised-solidified waste. 
Giulia Costa is a postdoctoral fellow at the Civil Engineering Department of the University of Rome 'Tor Vergata'. She received her Master's degree in Environmental Engineering from the University of Rome 'La Sapienza' with a thesis carried out at the Technical University of Denmark. She received a Doctorate in Environmental Engineering from the University of Rome 'Tor Vergata' with a thesis concerning accelerated carbonation of minerals and alkaline industrial residues for carbon dioxide sequestration. Her current research activities regard the characterisation and leaching behaviour of waste incineration residues, mineral carbonation and the management of contaminated sediments.

Renato Gavasci is a Full Professor in Sanitary and Environmental Engineering at the University of Rome 'Tor Vergata', Italy. He earned his Master's degree in Civil Engineering at the University of Rome 'La Sapienza'. He is the coordinator of the doctorate programme in Environmental Engineering of the University of Rome 'Tor Vergata'. He is a consultant of ACEA ATO2, the company that manages the integrated water cycle of the city of Rome and a member of the Italian Superior Counsel on Public Works. His research activities concern the treatment and disposal of wastewater and solid waste.

Paola Muraro works as a consultant for the city of Rome's waste management company (AMA), coordinating research projects concerning non-agronomic methods for recycling the organic fraction of MSW. She received her degree in Agriculture from the University of Bologna. She has worked for several public and private companies, specialising in the management of organic waste. She has collaborated with public institutions providing both technical assistance for the training of technicians in waste management and scientific support in the publishing of various papers. She is the co-author of numerous papers on organic waste recycling management.

\section{Introduction}

The integration of the principles of sustainable development in environmental policies and programmes worldwide is one of the targets of the UN Millennium Development Goals (UN, 2009). In this framework, waste management strategies play a key role, since they exert a direct impact on human health, the environment and the economy of a region. Waste production is in fact continuing to grow in both developed and developing countries (OECD, 2008). A series of coordinated and rationalised technical and organisational measures are hence needed to address this complex issue in a sustainable way. EU regulations in this field, stemming from the Framework Directive on waste disposal (European Council, 1975), stress the need to define and implement integrated management systems, in which strategic decisions and lines of action are selected on the basis of a hierarchical set of priorities. The first priority is the minimisation/prevention of waste production, which can be achieved by implementing specific regulatory or economic policies. The next goals are firstly material recovery and then energy recovery. The management practices that are generally adopted to achieve these objectives are reuse and recycling of specific waste fractions through source separation, other forms of material recovery from commingled waste such as mechanical separation and energy recovery from the dry and/or wet waste fractions, mainly by thermal treatment. One of the main aims of such a management scheme is in fact the prevention or reduction of the potential adverse effects on human health and the environment deriving from the disposal of 
untreated waste. Final disposal of waste in sanitary landfills is hence considered the leastpreferred option which should be applied only to the residual fractions of prior treatment stages, when further recovery is deemed technically and economically unfeasible. To this aim, the Landfill Directive (European Council, 1999) has established specific reduction targets of the biodegradable fraction of the waste that can be accepted in landfills.

EU member countries must adopt the above-mentioned directives by issuing specific national regulations; however, the implementation of these policies and the selected strategies enacted to achieve these objectives differ largely from country to country, since they are influenced by economic, social and geomorphologic conditions (Cossu, 2009). In general, it can be observed that, although waste prevention has been assigned the highest priority under European waste management law and finalised initiatives have started to be undertaken in various countries, significant variations in waste generation trends have not been registered yet (Eurostat, 2009). Conservative measures which do not require a reduction in consumption, such as the substitution of one-way products with reusable ones, have in fact been indicated to be able to prevent only 1-3\% of Municipal Solid Waste (MSW) generation (Salhofer et al., 2008). European statistics report an average total production of $6 \mathrm{t}$ waste per person for 2006 (Eurostat, 2009) in the European Union (EU27), 10\% of which consists of MSW (ISPRA, 2008).

Regarding the adoption of material and energy recovery strategies, on average, in $2006,44 \%$ of the waste generated in EU27 was recovered, 5\% was thermally treated and $51 \%$ was landfilled (Eurostat, 2009). Statistics on MSW management show an increase in thermal treatment $(20 \%)$ and a roughly comparable use of recovery $(40 \%)$ and final disposal (40\%) (ISPRA, 2008). However, as previously mentioned, the waste management practices currently adopted by single member countries differ significantly. Countries such as Germany, Denmark, The Netherlands, Sweden and Belgium landfill less than 5\% of the produced MSW, incinerating over 30\% and recovering the rest with different strategies (including mechanical or manual sorting, composting, anaerobic digestion, etc.). In most of the recent EU member countries, Southern Europe and the UK, instead, sanitary landfilling is still the most-adopted waste management strategy ( $>50 \%)$ (ISPRA, 2008). Although these percentages are bound to change in the near future in order to comply with EU directives, it is expected that significant differences in the waste management strategies adopted by the various countries will remain, owing to the different relevance attributed by each country to technical, economical and environmental aspects, as well as the influence of social and political issues. It is important to underline that material recovery and thermal treatment are two strategies that may be adopted together, not in competition. Vehlow et al. (2007) have in fact shown that EU member states that extensively practice material recovery (including composting) also incinerate a major part of their residual waste. The correlation between high recycling rates and the adoption of waste-to-energy treatments for commingled residual waste was also evidenced in a recent study (Castaldi and Themelis, 2010). Magrinho and Semiao (2008) evidenced that although recovery of paper and plastics reduces the Lower Heating Value (LHV) of the residual waste, this decrease may be compensated by the diminution of the moisture content of the waste due to separation of humid fractions.

In any case, most studies (e.g. Koufodimos and Samaras, 2002; Burnley, 2007) agree that one of the main factors determining the viability of combining specific integrated waste management strategies is the composition of the waste, which is affected by many variables (social, economical, etc.) as well as by the type and entity of the adopted source separation practices. Another important factor that must be taken into consideration when 
assessing the efficacy of specific separation strategies in increasing the sustainability of waste management practices is the percentage of effective recycling and reuse of the separated waste streams. The reuse of the separated materials in fact results in the replacement of primary raw materials and hence the avoidance of their production. Data regarding packaging waste (which makes up about one-third of the MSW produced in the EU) showed, for EU27 countries, with 2006 as reference year, significant recovery rates $(70 \%)$ and somewhat lower recycling percentages (57\%) (ISPRA, 2008). Materials such as metals and glass exhibit very similar recovery and recycling rates, whereas paper, plastics and wood show significant decreases in material recycling compared to recovery rates. Over half of the recovered plastics, $30 \%$ of the wood and $10 \%$ of the paper, in fact, are thermally treated for energy recovery (ISPRA, 2008).

On the other hand, the valorisation of the residual waste from at the source separation has also been appointed an important role in the European waste management hierarchy; in this case though, energy recovery assumes particular importance, given the possibility of recovering and reusing only a limited fraction of the commingled waste. Vehlow et al. (2007) calculated the potential of residual MSW to replace fossil fuels in the power market of selected EU countries and found values ranging from 3\% to 5\% for countries such as Germany and Italy. These figures may be deemed interesting also in consideration of the fact that the biogenic fraction of MSW accounts for more than 50-60\% of its energy inventory and hence more than half the $\mathrm{CO}_{2}$ emitted from the combustion of MSW may be regarded as climate neutral (Vehlow et al., 2007; Castaldi and Themelis, 2010). Furthermore, a major environmental advantage of thermal treatment of residual waste compared to landfilling is an avoided methane credit, which has been calculated, on a 20-year timescale basis for the greenhouse effect of landfill-derived methane, as equivalent to 1.2 tonnes $\mathrm{CO}_{2}$ avoided per tonne of input waste (Porteous, 2005).

The above-discussed data, however, provide only a schematic picture of the current trends in European waste management. Local practices and strategies can differ quite significantly. It may be argued that the correct balance between different waste management strategies is not of easy definition and may vary greatly, even within the same country. In Italy, for example, regional differences in MSW separation and treatment practices are quite marked and at times even contradictory. Several assessment methods have been developed to select the most suitable integrated waste management strategies for a specific situation; however, depending on which parameters are considered in the analysis, different results may be obtained. Three main types of models are generally used (Morrissey and Browne, 2004), (a) those based on cost-benefit analysis, (b) those based on life cycle analysis (see e.g. Nyland et al., 2003; Winkler and Bilitewski, 2007) and (c) those based on multi-criteria techniques (e.g. Minciardi et al., 2008). These methodologies are generally applied to compare different management scenarios in order to identify those that result more sustainable from an economical, environmental or combined (e.g. economical, environmental and social) perspective, respectively.

In this paper, after a brief overview of current Italian MSW management practices, on the basis of detailed composition data regarding the MSW produced in the city of Rome, possible integrated management scenarios which make use of material and energy recovery, in abidance with EU waste management guidelines, are compared and discussed. In particular, assuming specific source separation recovery rates, for each scenario, the heating values of the residual MSW obtained after different processing strategies are estimated and compared in order to identify the separation and treatment techniques that would allow to maximise material and energy recovery from the waste. 


\section{Overview of Italian MSW management strategies}

\subsection{MSW production and main composition}

In its annual report on waste production and management, the Italian Environmental Protection Agency estimated that about 32.5 Mt of MSW were produced in Italy in 2007, $8.4 \%$ more than in 2003 (ISPRA, 2008), with the highest per capita productions in the most densely inhabited areas (e.g. $649 \mathrm{~kg} /$ person $\times$ y in the city of Rome in 2007).

The composition of the waste produced on a national scale also shows a high variability depending on the geographic location, socio-economical context, cultural standards, as well as on the principal activities carried out in the examined area (e.g. presence of industries, agriculture, etc.). In Table 1, typical MSW composition ranges for different reference contexts, as defined by Italian technical guidelines on urban hygiene (ANPA and ONR, 2001), are reported. The main characteristics of the urban reference contexts defined in the above-mentioned document are the following:

1 high-density areas: $50-80 \%$ of the population resides in buildings with more than four families (40 inhabitants/building), the remaining population (20-50\%) resides in buildings with less than four families (four inhabitants/building);

2 low-density areas: $20-40 \%$ of the population resides in buildings with more than four families (20 inhabitants/building), the remaining population $(60-80 \%)$ resides in buildings with less than four families (four inhabitants/building);

3 touristic areas: $20-40 \%$ of the population resides in buildings with more than four families (20 inhabitants/building), the remaining population $(60-80 \%)$ resides in buildings with less than four families (four inhabitants/building); waste production in the touristic season is assumed to be equal to 2-5 times the average annual value.

As can be noted by examining Table 1, MSW composition in touristic and high-density areas are assumed to be analogous, presenting generally higher contents of packaging materials, such as plastics and paper/cardboard, compared to districts characterised by a lower number of inhabitants per building.

Table 1 Typical composition of the MSW generated in Italy in different urban areas

\begin{tabular}{lccc}
\hline & \multicolumn{3}{c}{ Reference context } \\
\cline { 2 - 4 } Fractions & High density & Low density & Touristic area \\
\hline Paper/cardboard & $24-26 \%$ & $18-22 \%$ & $24-26 \%$ \\
Organic/wood & $30-40 \%$ & $35-45 \%$ & $30-40 \%$ \\
Plastics & $10-15 \%$ & $8-12 \%$ & $10-15 \%$ \\
Glass & $9-11 \%$ & $9-11 \%$ & $9-11 \%$ \\
Metals & $3-5 \%$ & $3-5 \%$ & $3-5 \%$ \\
Other & $14-16 \%$ & $14-18 \%$ & $14-16 \%$ \\
Total & $100 \%$ & $100 \%$ & $100 \%$ \\
\hline
\end{tabular}

Source: ANPA and ONR (2001)

\subsection{Strategies for waste separation at the source}

Italian legislation, in compliance with EU directives, has established to enhance source separation of selected fractions of MSW, by setting increasing annual separation objectives for the next few years, with the final aim of achieving values above $65 \%$ by the end of 2012 (Italian Parliament, 2006). 
In the year 2007 , roughly $26 \%$ of the MSW generated in Italy was source-separated (ISPRA, 2008). While this percentage shows a constantly increasing trend, it must be highlighted that, as appears evident from Figure 1, the extent of application of MSW source separation strategies varies greatly on a regional basis. It can be observed that while the northern regions have already reached and exceeded the goal of $40 \%$ recovery by 2007 , central and particularly southern regions are still very far from that objective with $20.8 \%$ and $11.6 \%$ separation percentages, respectively.

These data show that there has been a growing effort in the last few years on a national scale, although with different results, to increase the recovery of specific fractions of MSW, in compliance with EU guidelines. What cannot be assessed from these figures, though, are the percentages of source-separated material that are actually recycled and the percentages of the fractions which are part of the separated waste stream but are sent to final disposal. Regarding this issue, the few available data show that merely some specific sub-fractions of the main types of separated waste (i.e. plastics, glass, paper, etc.) have their own recycling market, whereas the residual material is generally sent to final disposal, primarily to landfills or, as a second option, to waste-toenergy facilities. For packaging waste, which on average accounts for $40 \%$ of all sourceseparated MSW, the management options adopted for different waste sub-fractions, as shown in Figure 2, are generally in line with those previously discussed for EU27 countries (CONAI, 2008). Plastics shows the lowest recycling percentages $(<30 \%)$ with landfill disposal rates still above $40 \%$. Conversely, paper, which represents by far the most abundant type of commercialised packaging waste fraction (4.5 Mt), exhibits much higher recycling rates $(>70 \%)$ (CONAI, 2008).

Source separation of organic waste from MSW collected from households with door-to-door strategies or from commercial activities, such as markets, restaurants, etc., is another important practice to attain material recovery and a decrease in landfilling practices. These selected fractions are treated along with yard and garden waste, as well as other organic residues, in composting plants to produce a stabilised material with soil amendment properties. In 2007, about 3.2 Mt of source-separated organic waste was treated in composting facilities, $40 \%$ of which was source-selected MSW (ISPRA, 2008).

\subsection{Processing strategies for residual commingled MSW}

Regarding the management of the residual commingled waste obtained after source separation of selected MSW fractions, current data indicate that, at a national level, landfill disposal is still the most-adopted practice (ISPRA, 2008). Pre-treatment strategies aimed at achieving energy recovery and/or improving the environmental characteristics of the waste prior to its final disposal, however, are being increasingly implemented, particularly in Northern and Central Italy. National landfill acceptance criteria have been in fact recently issued in compliance with the principles stated by the EU Landfill Directive and specific limit values established by the EU Council Decision 2003/33/EC (European Council, 2003). These acceptance criteria are mainly based on the results of standard leaching tests, such as the EN 12457 tests, and regard eluate concentrations of different kinds of contaminants, including heavy metals, soluble salts and Dissolved Organic Carbon (DOC). For this latter parameter, limit values of 80 and $100 \mathrm{mg} / \mathrm{l}$ for non-hazardous and hazardous waste landfills have been established, respectively. Direct landfilling of the residual MSW from source separation of selected fractions without pre-treatment has been prohibited by the Italian Decree 36/03 (Italian Parliament, 2003). This norm has also set specific requirements regarding the maximum LHV of the waste that can be accepted in landfills $(13,000 \mathrm{~kJ} / \mathrm{kg})$. The selection of the treatment and/or pre-treatment processes to 
apply to commingled residual waste must hence be made also in consideration of the final characteristics of the end products, so as to maximise material and energy recovery from every material flow, in abidance with the requirements of the law (Italian Parliament, 2003).

Figure 1 Waste source separation trends in Italy from 2003 to 2007

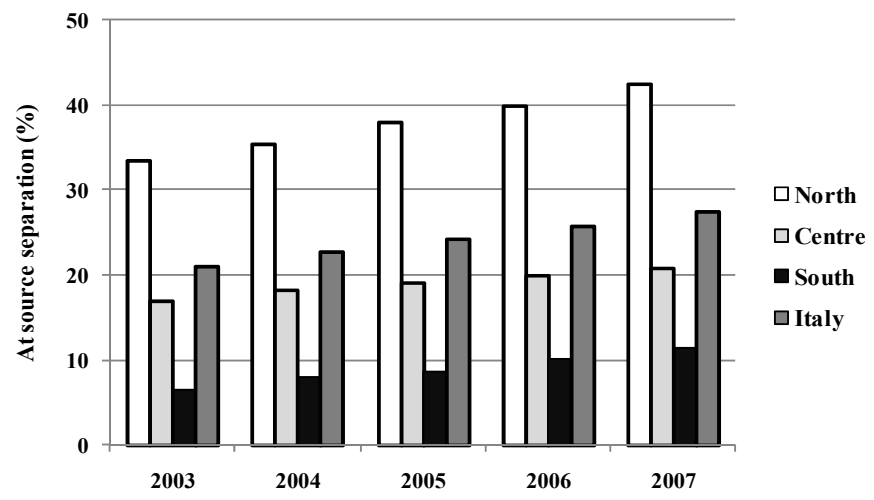

Source: ISPRA (2008)

Figure 2 Amounts produced and strategies adopted for the management of the main sub-fractions of source-separated packaging MSW in Italy for the year 2007

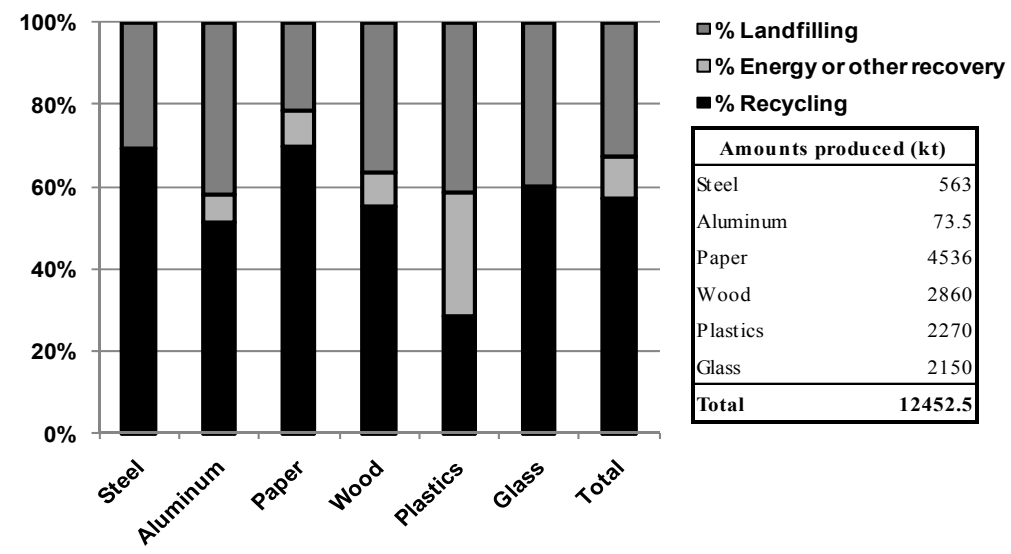

Source: CONAI (2008)

The main strategies currently pursued in Italy for managing residual MSW are Mechanical Biological Treatment (MBT) and thermal treatment. In 2007, over $40 \%$ and $18 \%$ of residual MSW were treated in these types of facilities, respectively (ISPRA, 2008). MSW management strategies, however, are established at a regional level, and hence significant differences can be evidenced from one geographical area to another. MBT may be applied with or without Refuse Derived Fuel (RDF) production, whereas, depending on the type of treated waste, three main processes may be identified for energy recovery from MSW:

1 direct incineration of residual MSW;

2 thermal treatment (mainly incineration) of the dry fraction of the residual MSW, separated at the incinerator facility or in dedicated sorting plants;

3 thermal treatment (mainly incineration) of RDF produced at MBT facilities. 
As shown in Figure 3, in Northern Italy, and particularly in Lombardy, direct incineration of residual MSW is by far the most-adopted waste-to-energy recovery strategy. In Central Italy, RDF and dry fraction incineration are the most applied technologies, whereas in southern regions direct incineration of residual MSW is mostly pursued. In Rome's region, Lazio, currently, only waste combustion facilities treating RDF have been authorised.

As for the management of the humid fraction of residual MSW separated in MBT plants, this material is generally treated by aerobic biodegradation processes and disposed of in landfills along with processing scraps (ISPRA, 2008). The average composition of treatment scraps may often not comply with the above-mentioned Italian landfill regulatory limits and, in particular, with DOC leaching limits for the residues from organic waste stabilisation and with the LHV limits for the other fractions. Therefore, specific treatments processes might also prove necessary to reduce the organic and combustible fractions of these processing residues before final disposal.

Concerning future trends in residual MSW management, it may be anticipated that, in order to comply with more stringent EU requirements (European Council, 2008) regarding energy recovery efficiencies, pre-treated waste incineration might progressively substitute direct incineration of residual MSW. As regards recent technological developments in MBT of MSW, biodrying is a technology that allows to remove the excessive moisture of the input waste, facilitating mechanical processing and improving thermal recovery from the treated waste material (see e.g. Velis et al., 2009 and references therein). Several types of these facilities are being built in Northern Italy, as in other European countries; hence, it may be expected that in the near future combustion of biodried MSW residual waste may be significantly implemented.

Figure 3 Amounts $(\mathrm{kt})$ of different types of MSW treated in incineration facilities in Italy in the year 2007

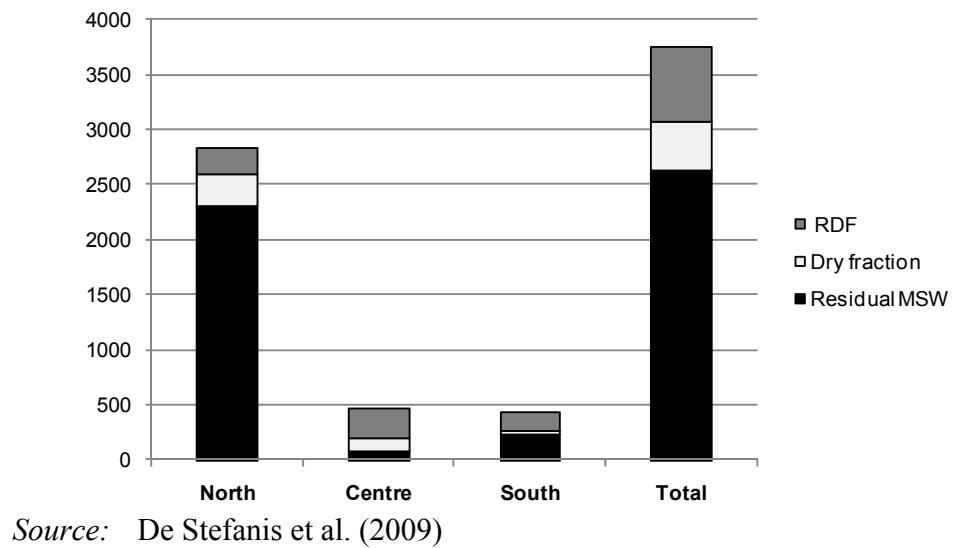

\section{Assessment of MSW management strategies for the city of Rome}

\subsection{Reference data}

In Table 2, the average composition of the MSW produced in the city of Rome, resulting from a detailed characterisation campaign carried out in 2004 (Lombardi and Muraro, $2007)$, is reported. The total quantity of MSW generated in the city of Rome in this reference year amounted to $1.77 \mathrm{Mt}$ (Lombardi and Muraro, 2007). This specific dataset 
was chosen as reference of the current average composition of the MSW generated in Rome prior to separate collection of selected fractions, since it is the most detailed relatively recent characterisation of the MSW produced in Rome and since significant variations in parameters that may influence the composition of this type of waste stream (e.g. Italy's gross domestic product and total consumer expenditure capacity) did not occur in the last few years, at least up to the year 2007 (ISPRA, 2008).

Comparing these composition data with those reported in Table 1 for MSW generated in different urban contexts, good agreement with the data reported for densely inhabited and touristic areas may be noted, in particular regarding the paper and cardboard $(\sim 27 \%)$, plastics $(10.5 \%)$ and organic waste $(26 \%)$ fractions of the waste.

Table 2 Average composition of the MSW produced in the city of Rome

\begin{tabular}{|c|c|c|c|c|c|}
\hline Fractions & $(\%)$ & Fractions & $(\%)$ & Fractions & $(\%)$ \\
\hline Organic waste & 26.15 & Bulky material & 2.37 & Plastics & 10.46 \\
\hline food waste & 22.81 & durable goods & 0.43 & plastic packaging & 3.71 \\
\hline yard waste & 2.61 & wooden bulky material & 0.09 & garbage bags & 0.71 \\
\hline wood & 0.66 & other bulky material & 1.86 & PVC bottles & 0.44 \\
\hline other & 0.07 & Glass & 4.99 & PET bottles & 2.01 \\
\hline Paper & 14.96 & transparent glass & 2.46 & HDPE containers & 1.06 \\
\hline wrapping paper & 2.13 & coloured glass & 2.50 & polystirene & 0.26 \\
\hline newspapers/magazines & 8.00 & other glass & 0.03 & plastic films & 1.19 \\
\hline photographic paper & 4.36 & Metals & 2.28 & other packaging material & 0.20 \\
\hline other & 0.47 & steel containers & 1.28 & other plastics & 0.90 \\
\hline Cardboard & 11.81 & other ferrous metals & 0.33 & Wood & 1.77 \\
\hline cardboard packaging & 7.86 & alluminum containers & 0.24 & wooden crates & 0.67 \\
\hline stiff cardboard & 3.82 & alluminum access ories & 0.01 & other wood & 1.10 \\
\hline other & 0.13 & other alluminum & 0.07 & Other packagings & 1.16 \\
\hline Diapers & 2.07 & other non ferrous metals & 0.36 & mixed packaging & 0.83 \\
\hline Textiles & 4.14 & Hazardous materials & 0.02 & packaging material 1 & 0.27 \\
\hline clothes & 4.14 & chemical products & 0.00 & packaging material 2 & 0.06 \\
\hline textile packaging & 0.00 & medicines & 0.01 & Fines & 10.07 \\
\hline Leather and skin & 0.70 & fluorescent lamps & 0.00 & Const. and dem. waste & 4.62 \\
\hline Rubber & 1.08 & batteries & 0.00 & Other non classif. mat. & 1.35 \\
\hline household rubber & 0.77 & accumulators & 0.01 & & \\
\hline tires & 0.31 & other hazardous materials & 0.00 & & \\
\hline
\end{tabular}

Source: Lombardi and Muraro (2007)

\subsection{Definition of MSW source separation scenarios}

To evaluate the feasibility of achieving the objectives set by current Italian legislation regarding source separation from MSW, different collection scenarios of selected fractions of the waste generated in the city of Rome were hypothesised. On the basis of the recovery percentages assumed for every selected fraction in each scenario and on the composition data reported in Table 2 for commingled MSW, the composition of the source-separated waste and of the residual commingled waste resulting from each simulated scenario were calculated.

Two separation strategies were selected and compared, the first one with the goal of maximising the percentages of source separation from MSW in order to achieve legislative targets, without considering the effective reuse potential of the selected materials, and the 
second one with the objective of maximising the recovery of only the waste fractions that can be recycled. In both cases, recovery percentages of the different waste fractions were hypothesised assuming kerbside collection of the waste.

In Table 3, the recovery percentages achieved for each type of waste fraction, resulting from the percentages assumed for each sub-fraction in both of the analysed cases, are reported. In the first scenario (Scenario 1), the highest separation percentages deemed feasible by kerbside collection for each type of material were selected and applied to all the sub-fractions of the specific materials that are subject to source separation in the city of Rome, regardless of their reusability. In Scenario 2, instead, only the sub-fractions which are potentially recyclable were hypothesised to have been collected separately; hence, the overall separation yields were assumed to be lower than those considered in Scenario 1. As shown in Table 3, for construction and demolition waste, textiles, wood, metals and rubber, the same percentages were used for both scenarios, since all subfractions of these materials were supposed to be recyclable; whereas, for paper, glass and plastics, increasingly lower separation rates were assumed in Scenario 2, in accordance with the data shown in Figure 2 concerning current recycling rates of different types of packaging waste.

Table 3 Recovery percentages of different fractions of MSW assumed for each source separation scenario

\begin{tabular}{|c|c|c|c|c|c|}
\hline Fractions & \multicolumn{2}{|c|}{ Separation yields $\%$} & \multirow[t]{2}{*}{ Fractions } & \multicolumn{2}{|c|}{ Separation yields $\%$} \\
\hline & Scenario 1 & Scenario 2 & & Scenario 1 & Scenario 2 \\
\hline Paper & 65.84 & 50.39 & Textiles & 60.00 & 60.00 \\
\hline wrapping paper & 70.00 & 50.00 & clothes & 60.00 & 60.00 \\
\hline newspapers/magazines & 70.00 & 70.00 & textile packaging & 100.00 & 100.00 \\
\hline photographic paper & 60.00 & 20.00 & Rubber & 17.21 & 17.21 \\
\hline other & 30.00 & 0.00 & household rubber & 0.00 & 0.00 \\
\hline Cardboard & 66.33 & 49.45 & tires & 60.00 & 60.00 \\
\hline cardboard packaging & 70.00 & 50.00 & Wood & 60.00 & 60.00 \\
\hline stiff cardboard & 60.00 & 50.00 & wooden crates & 60.00 & 60.00 \\
\hline other & 30.00 & 0.00 & other wood & 60.00 & 60.00 \\
\hline Glass & 64.77 & 47.46 & Plastics & 24.68 & 10.89 \\
\hline transparent glass & 65.00 & 65.00 & plastic packaging & 0.00 & 0.00 \\
\hline coloured glass & 65.00 & 30.00 & garbage bags & 0.00 & 0.00 \\
\hline other glass & 30.00 & 65.00 & PVC bottles & 60.00 & 50.00 \\
\hline Metals & 53.88 & 53.88 & PET bottles & 65.00 & 30.00 \\
\hline steel containers & 70.00 & 70.00 & HDPE containers & 65.00 & 30.00 \\
\hline other ferrous metals & 50.00 & 50.00 & polystirene & 0.00 & 0.00 \\
\hline alluminum continers & 70.00 & 70.00 & plastic films & 0.00 & 0.00 \\
\hline alluminum acces sories & 10.00 & 10.00 & other packaging material & 30.00 & 0.00 \\
\hline other alluminum & 0.00 & 0.00 & other plastics & 30.00 & 0.00 \\
\hline other non ferrous metals & 0.00 & 0.00 & Const. and dem. waste & 80.00 & 80.00 \\
\hline
\end{tabular}

In order to analyse the effects of different collection strategies regarding the organic fraction of MSW, for each of the above-mentioned source separation strategies, two subscenarios (A and B), in which different organic waste recovery approaches were assumed (as shown in Table 4), were also examined. In sub-scenario A, the organic fraction of the waste was hypothesised to have been collected separately in order to maximise material 
recovery (total separation yield of $61 \%$ ), while in sub-scenario B it was hypothesised that only the organic waste generated by specific activities (such as markets, canteens and restaurants) was collected separately (total separation yield of 26\%).

Table 4 Recovery percentages of the organic fraction of MSW assumed in each sub-scenario

\begin{tabular}{lcc}
\hline \multicolumn{1}{c}{ Fractions } & \multicolumn{2}{c}{ Separation yields $\%$} \\
\hline & Scenario 1 & Scenario 2 \\
\hline \multicolumn{1}{c}{ Organic waste } & 60.92 & 25.85 \\
food waste & 60.00 & 25.00 \\
yard waste & 70.00 & 40.00 \\
wood & 60.00 & 2.00 \\
other & 30.00 & 0.00 \\
\hline
\end{tabular}

\subsection{Evaluation of energy recovery options from residual MSW}

To examine possible management practices for the residual commingled MSW resulting from the implementation of the above-mentioned at the source collection strategies, a second set of simulations were carried out, focusing particularly on the amounts and energy content of each fraction.

Also for this simulation the waste composition was assumed to be that showed in Table 2 and the same scenarios as those analysed for at the source separation (1A, 1B, $2 \mathrm{~A}$ and $2 \mathrm{~B}$ ) were examined in terms of the energetic characteristics of the inflows and the products of different types of waste processing strategies aimed at energy recovery. Based on the analysis of the current and future practices that are and may be adopted for energy recovery from residual MSW in Italy, the following processing strategies were considered: MBT with or without RDF production; biodrying and thermal treatment. For this latter type of treatment in particular, different options were considered and compared in terms of attainable energy recovery: direct incineration of commingled residual MSW; thermal treatment of only RDF; thermal treatment of the dry fraction of residual MSW and thermal treatment of biodried residual MSW. Hence, on the basis of the residual waste composition resulting from each of the above-described selection scenarios, the energy recovery that could be attained by thermal treatment of the following material flows was evaluated:

1 commingled residual MSW from source separation operations;

2 material flows resulting from a typical MBT plant, i.e. RDF, scrap material from RDF production, stabilised organic waste and scrap material from organic waste stabilisation;

3 a fraction denominated dry fraction - type 1, given by the sum of the RDF and the RDF scraps produced by the same selection operations as those described in point 2 , simulating the dry fraction generated during waste selection without RDF production;

4 a fraction denominated dry fraction - type 2, given by the sum of the RDF, the RDF scraps and the scraps from organic waste stabilisation, produced by the same selection operations as those described in point 2;

5 the output of a typical biodrying plant, denominated biodried fraction - type 1, hypothesising the separation of the inert fractions (glass, metals, bulky material and construction and demolition waste);

6 the material flows resulting from residual MSW biodrying, denominated biodried fraction - type 2, including the inert fractions. 
The data regarding the composition of the material flows produced in a typical MBT facility used in the simulations (see Table 5) were derived from a series of detailed characterisation campaigns carried out in the waste selection plants in operation in the city of Rome for residual MSW processing (Lombardi and Muraro, 2007).

To estimate the amounts and composition of the material flows generated during biodrying of residual commingled waste, data reported in a recent review on biodrying treatment of waste were used (Velis et al., 2009). In particular, hypothesising a processing time of 14 days using the 'high speed process management' mode, typical weight losses between $30 \%$ and $38 \%$ of the treated waste compared to the input material and overall net water losses (given by the difference between evaporation and/or convection losses and metabolic water gains) between $30 \%$ and 55\% were reported (Velis et al., 2009). Hence, to establish a typical composition for biodried MSW, biodegradation percentages and moisture contents were assumed for each fraction making up the treated waste, as shown in Tables 6 and 7, respectively. Total weight and moisture losses were calculated for the biodried residual MSW resulting from each of the analysed source separation scenarios in order to verify if the hypothesised biodegradation rates and moisture content losses were in line with those reported in the literature. Total weight losses ranging from 33\% (Scenario 2B) to 37\% (Scenario 1B) and moisture content losses between $43 \%$ (Scenario $1 \mathrm{~B}$ ) and $52 \%$ (Scenario 2A) were found.

To calculate the Higher Heating Value (HHV) and Lower Heating Value (LHV) of each of the material flows analysed in the simulations, the modified Dulong formulas were applied (equations 1 and 2) on the basis of the moisture content (M) and elemental composition (in terms of $\mathrm{C}, \mathrm{H}, \mathrm{O}, \mathrm{N}$ and $\mathrm{S}$ content) of each type of waste stream. These values were estimated from the elemental composition and moisture content of each of the fractions making up the different types of waste flows. For the material flows resulting from selection operations in traditional MBT plants, the percentage repartition reported in Table 5 was used, whereas the composition of biodried residual MSW was derived from the degradation percentages hypothesised in Table 6 . The moisture contents and elemental composition of each specific waste fraction considered in the simulations are shown respectively in Tables 7 and 8 . These values were selected on the basis of typical values reported in the literature (Tchobanoglous et al., 1993). The elemental composition was assumed to be the same in each of the fractions making up the different material flows, whereas the moisture content values were varied depending on the type of waste stream. The moisture contents of the commingled residual MSW and RDF were assumed to be the same. For the RDF production scraps, a 5\% increase was assumed in all fractions, whereas for the stabilised material scraps the moisture content was calculated subtracting the water content of the residual MSW by the evaporation losses reported in Table 5. For the biodried residual MSW, as previously mentioned, the values reported in Table 7 were hypothesised considering the moisture content of the residual MSW and the typical water losses reported by Velis et al. (2009).

$$
\begin{aligned}
& \mathrm{HHV}=80.56 \cdot \mathrm{C}+338.89(\mathrm{H}-\mathrm{O} / 8)+5.56 \cdot \mathrm{N}+22.22 \cdot \mathrm{S} \\
& \mathrm{LHV}=\mathrm{HHV}-6.06 \cdot(\mathrm{M}+9 \cdot \mathrm{H})
\end{aligned}
$$


Table 5 Percentage repartition of each fraction of residual MSW in the material flows resulting from selection operations carried out in a typical MBT plant

\begin{tabular}{lccccccc}
\hline \multicolumn{1}{c}{ Waste fractions } & $\begin{array}{c}\text { RDF } \\
(\%)\end{array}$ & $\begin{array}{c}\text { Stab. mat } \\
(\%)\end{array}$ & $\begin{array}{c}\text { Recov. } \\
\text { metals } \\
(\%)\end{array}$ & $\begin{array}{c}\text { RDF } \\
\text { scraps } \\
(\%)\end{array}$ & $\begin{array}{c}\text { Stab. mat. } \\
\text { scraps } \\
(\%)\end{array}$ & $\begin{array}{c}\text { Evap. } \\
\text { losses } \\
(\%)\end{array}$ & $\begin{array}{c}\text { Total } \\
(\%)\end{array}$ \\
\hline Fines & 5.4 & 44 & - & 8.6 & 20.1 & 21.9 & 100 \\
Food waste & 5 & 44 & - & 2.7 & 6.3 & 42 & 100 \\
Yard waste & 5 & 65 & - & 7 & 3 & 20 & 100 \\
Paper & 77 & 5 & - & 7 & 3 & 8 & 100 \\
Cardboard & 76 & 8 & - & 5.6 & 2.4 & 8 & 100 \\
Coupled packaging & 74 & 3 & - & 10.5 & 4.5 & 8 & 100 \\
Plastics & 78 & 3 & - & 9.8 & 4.2 & 5 & 100 \\
Plastic films & 77 & 3 & - & 10.5 & 4.5 & 5 & 100 \\
Glass & 2 & 7 & - & 27 & 63 & 1 & 100 \\
Metals & 0.1 & 0.2 & 98 & 0.8 & 0.8 & 0.1 & 100 \\
Diapers & 6 & 1 & - & 76.5 & 8.5 & 8 & 100 \\
Textiles & 55 & 5 & - & 31.5 & 3.5 & 5 & 100 \\
Rubber & 88 & 3 & - & 5.6 & 2.4 & 1 & 100 \\
Leather & 86 & 5 & - & 5.6 & 2.4 & 1 & 100 \\
Const. and dem. waste & 4 & 10 & - & 25.5 & 59.5 & 1 & 100 \\
Hazardous material & 4 & 10 & - & 59.5 & 25.5 & 1 & 100 \\
Wood & 70 & 17 & - & 7.7 & 3.3 & 2 & 100 \\
Bulky material & 1 & 1 & - & 87.3 & 9.7 & 1 & 100 \\
Other & 60 & 10 & - & 19.6 & 8.4 & 2 & 100 \\
\hline
\end{tabular}

Table 6 Biodegradation percentage assumed for each fraction of biodried residual MSW

\begin{tabular}{lc}
\hline Waste fractions & Biodegradation on dry basis (\%) \\
\hline Fines & 60 \\
Food waste & 75 \\
Yard waste & 50 \\
Paper & 55 \\
Cardboard & 60 \\
Coupled packaging & 10 \\
Plastics & 0 \\
Plastic films & 0 \\
Glass & 0 \\
Metals & 0 \\
Diapers & 5 \\
Textiles & 10 \\
Rubber & 0 \\
Leather & 0 \\
Const. and dem. waste & 0 \\
Hazardous material & 0 \\
Wood & 10 \\
Bulky material & 0 \\
Others & 0 \\
\hline
\end{tabular}


Table 7 Moisture contents (M) of the single fractions considered in the simulations

\begin{tabular}{lcccc}
\hline \multicolumn{1}{c}{ Waste fractions } & $\begin{array}{c}M(\%) \text { res. } \\
\text { MSW and } \\
\text { RDF }\end{array}$ & $\begin{array}{c}M(\%) \text { RDF } \\
\text { scraps }\end{array}$ & $\begin{array}{c}\text { M (\%) stab. } \\
\text { mat. scraps }\end{array}$ & $\begin{array}{c}M(\%) \\
\text { biodr. }\end{array}$ \\
\hline Fines & 40 & 42 & 31 & 20 \\
Food waste & 77 & 81 & 45 & 29 \\
Yard waste & 45 & 47 & 36 & 34 \\
Paper & 20 & 21 & 18 & 15 \\
Cardboard & 18 & 19 & 17 & 12 \\
Coupled packaging & 20 & 21 & 18 & 10 \\
Plastics & 12 & 13 & 11 & 8 \\
Plastic films & 12 & 13 & 11 & 8 \\
Glass & 2 & 2 & 2 & 2 \\
Metals & 2 & 2 & 2 & 2 \\
Diapers & 36 & 38 & 33 & 24 \\
Textiles & 20 & 21 & 19 & 12 \\
Rubber & 2 & 2 & 2 & 2 \\
Leather & 2 & 2 & 2 & 2 \\
Const. and dem. waste & 2 & 2 & 2 & 2 \\
Hazardous material & 2 & 2 & 2 & 2 \\
Wood & 3 & 3 & 3 & 3 \\
Bulky material & 3 & 3 & 3 & 3 \\
Other & 3 & 3 & 3 & 3 \\
\hline & & & &
\end{tabular}

Table 8 Elemental composition (C, H, O, N and S) of the single fractions considered in the simulations

\begin{tabular}{lcccccc}
\hline \multirow{2}{*}{ Waste fractions } & $\begin{array}{c}C \\
(\%)\end{array}$ & $\begin{array}{c}H \\
(\%)\end{array}$ & $\begin{array}{c}O \\
(\%)\end{array}$ & $\begin{array}{c}N \\
(\%)\end{array}$ & $\begin{array}{c}S \\
(\%)\end{array}$ & $\begin{array}{c}\text { Ash } \\
(\%)\end{array}$ \\
\hline Food waste & 48 & 6.4 & 37.6 & 2.6 & 0.4 & 5 \\
Paper & 43.5 & 6 & 44 & 0.3 & 0.2 & 6 \\
Cardboard & 44 & 5.9 & 44.6 & 0.3 & 0.2 & 5 \\
Plastics & 60 & 7.2 & 22.8 & - & - & 10 \\
Textiles & 55 & 6.6 & 31.2 & 4.6 & 0.2 & 2.5 \\
Leather & 60 & 8 & 11.6 & 10 & 0.4 & 10 \\
Yard waste & 47.8 & 6 & 38 & 3.4 & 0.3 & 4.5 \\
Wood & 49.5 & 6 & 42.7 & 0.2 & 0.1 & 1.5 \\
Coupled packaging & 50.4 & 6.8 & 35.2 & 0.6 & 0.2 & 6.8 \\
Diapers & 70.8 & 8.9 & 9.1 & 1.2 & - & 10 \\
Rubber & 69.7 & 8.7 & - & - & 1.6 & 20 \\
Other & 46 & 6.3 & 4.6 & 1.3 & 0.1 & 41.7 \\
Fines & 38.4 & 7.7 & 15.4 & - & - & 38.5 \\
\hline
\end{tabular}




\section{Results and discussion}

\subsection{Source separation strategies for material recovery}

The main results derived assuming the separation yields defined for Scenario 1 (see Table 2), in terms of the overall achievable source separation percentages and the composition of the resulting residual commingled waste, are reported in Table 9. Depending on the type of source separation strategy adopted for the organic fraction of the waste, maximum source separation percentages between $38 \%$ (option B) and $48 \%$ (option A) were found, assuming kerbside collection. Organic waste, together with paper and cardboard, is the most abundant fractions of the MSW generated in the city of Rome (making up over $50 \%$ of the waste); hence the strategies and separation objectives adopted for these waste streams significantly affect the resulting overall source separation yields. Even hypothesising a high organic waste separation efficiency (sub-scenario A), though, the overall separation percentage did not exceed $50 \%$, indicating that in order to reach the increasing separation targets established by current Italian legislation, different collection strategies, such as door-to-door collection, will have to be implemented.

The main results derived assuming the separation yields defined for Scenario 2 (see Table 2), in terms of the overall achievable source separation percentages and the composition of the resulting residual commingled waste, are reported in Table 10. The data resulting from this scenario indicated that, depending on which fractions can be effectively recycled, separation percentages could range from $32 \%$ (option B) to $41 \%$ (option A), with a 6-7\% reduction compared to Scenario 1 . In this case too, the $9 \%$ difference between sub-scenarios A and B was due to the different organic waste recovery options considered in the simulations.

The most interesting result that can be derived from the comparison between Scenarios 1 and 2 is the effect of the presence of a recycling market on the separation percentages achievable for specific waste fractions. In Scenario 2, as shown in Table 3, some of the separation yields were reduced to take into account the increased selectivity of the adopted collection strategy aimed at recovering marketable material. In terms of the total amount of recyclable paper, cardboard, plastics and glass that were sourceseparated from MSW, overall percentages, referred to the total amount of commingled MSW, shifted from $23.5 \%$ in Scenario 1 to $16.9 \%$ in Scenario 2. In the calculation of these values though, the further quantitative reduction that these waste streams undergo during subsequent treatment processes aimed at maximising material recovery for commercial purposes was not accounted for.

It may be concluded hence that, in order to favour material recycling, overall source separation percentages should not be maximised; instead, source collection from selected activities only should be enhanced. This practice though, as shown in Tables 9 and 10, leads to the generation of higher amounts of residual commingled MSW.

\subsection{Processing strategies for energy recovery from residual MSW}

The material flows resulting from typical selection operations carried out in a traditional MBT plant on the commingled residual MSW generated by each of the analysed source separation Scenarios (1A, 1B, 2A and 2B), assuming for each flow the composition reported in Table 5, are summarised in Figure 4. It should be noted that in this paper the term stabilised material was used merely to indicate that the waste undergoes biological treatment and does not imply that the treated material could be recoverable for specific 
applications. Only source-separated organic waste (such as that resulting from Scenarios $1 \mathrm{~B}$ and $2 \mathrm{~B}$ ) presents generally, after treatment, suitable characteristics to allow its use, for example, in environmental reclamation projects.

Table 9 Main composition of the residual MSW resulting from source separation of selected waste fractions as defined in Scenario 1, in the case of maximum organic waste recovery (Scenario 1A) or organic waste recovery from specific activities only (Scenario 1B)

\begin{tabular}{|c|c|c|c|c|c|c|c|c|c|}
\hline \multicolumn{2}{|l|}{ Scenario 1} & \multicolumn{4}{|c|}{$A$} & \multicolumn{4}{|c|}{$B$} \\
\hline \multirow[b]{2}{*}{ Fractions } & \multirow[b]{2}{*}{$\%$} & \multicolumn{2}{|c|}{ source sep } & \multicolumn{2}{|c|}{ residual MSW } & \multicolumn{2}{|c|}{ source sep } & \multicolumn{2}{|c|}{ residual MSW } \\
\hline & & $\begin{array}{c}\% \text { of } \\
\text { fraction }\end{array}$ & $\begin{array}{l}\% \text { of } \\
\text { total }\end{array}$ & $\begin{array}{c}\% \text { of } \\
\text { fraction }\end{array}$ & $\begin{array}{l}\% \text { of } \\
\text { total }\end{array}$ & $\begin{array}{c}\% \text { of } \\
\text { fraction }\end{array}$ & $\begin{array}{l}\% \text { of } \\
\text { total }\end{array}$ & $\begin{array}{c}\% \text { of } \\
\text { fraction }\end{array}$ & $\begin{array}{l}\% \text { of } \\
\text { total }\end{array}$ \\
\hline Fines & 10.07 & 0.00 & 0.00 & 100.00 & 10.07 & 0.00 & 0.00 & 100.00 & 10.07 \\
\hline Organic waste & 26.15 & 60.92 & 15.93 & 39.08 & 10.22 & 25.85 & 6.76 & 74.15 & 19.39 \\
\hline Paper & 14.96 & 65.84 & 9.85 & 34.16 & 5.11 & 65.84 & 9.85 & 34.16 & 5.11 \\
\hline Cardboard & 11.81 & 66.33 & 7.84 & 33.67 & 3.98 & 66.33 & 7.84 & 33.67 & 3.98 \\
\hline Coupled packaging & 1.16 & 0.00 & 0.00 & 100.00 & 1.16 & 0.00 & 0.00 & 100.00 & 1.16 \\
\hline Plastics & 10.46 & 24.68 & 2.58 & 75.32 & 7.88 & 24.11 & 2.52 & 75.89 & 7.94 \\
\hline Glass & 4.99 & 64.77 & 3.23 & 35.23 & 1.76 & 64.77 & 3.23 & 35.23 & 1.76 \\
\hline Metals & 2.28 & 53.88 & 1.23 & 46.12 & 1.05 & 53.88 & 1.23 & 46.12 & 1.05 \\
\hline Diapers & 2.07 & 0.00 & 0.00 & 100.00 & 2.07 & 0.00 & 0.00 & 100.00 & 2.07 \\
\hline Textiles & 4.14 & 60.00 & 2.48 & 40.00 & 1.65 & 60.00 & 2.48 & 40.00 & 1.65 \\
\hline Rubber & 1.08 & 17.21 & 0.19 & 82.79 & 0.89 & 17.21 & 0.19 & 82.79 & 0.89 \\
\hline Leather & 0.70 & 0.00 & 0.00 & 100.00 & 0.70 & 0.00 & 0.00 & 100.00 & 0.70 \\
\hline Const. and dem. waste & 4.62 & 80.00 & 3.69 & 20.00 & 0.92 & 80.00 & 3.69 & 20.00 & 0.92 \\
\hline Hazardous waste & 0.02 & 0.00 & 0.00 & 100.00 & 0.02 & 0.00 & 0.00 & 100.00 & 0.02 \\
\hline Wood & 1.77 & 60.00 & 1.06 & 40.00 & 0.71 & 60.00 & 1.06 & 40.00 & 0.71 \\
\hline Bulky material & 2.37 & 0.00 & 0.00 & 100.00 & 2.37 & 0.00 & 0.00 & 100.00 & 2.37 \\
\hline Other & 1.35 & 0.00 & 0.00 & 100.00 & 1.35 & 0.00 & 0.00 & 100.00 & 1.35 \\
\hline Total & 100.00 & & 48.08 & & 51.92 & & 38.85 & & 61.15 \\
\hline
\end{tabular}

Table 10 Main composition of the residual MSW resulting from source separation of selected waste fractions as defined in Scenario 2, in the case of maximum organic waste recovery (Scenario 2A) or organic waste recovery from specific activities only (Scenario 2B)

\begin{tabular}{|c|c|c|c|c|c|c|c|c|c|}
\hline \multicolumn{2}{|l|}{ SCENARIO 2} & \multicolumn{4}{|c|}{$A$} & \multicolumn{4}{|c|}{$B$} \\
\hline \multirow[b]{2}{*}{ Fractions } & \multirow[b]{2}{*}{$\%$} & \multicolumn{2}{|c|}{ source sep } & \multicolumn{2}{|c|}{ residual MSW } & \multicolumn{2}{|c|}{ source sep } & \multicolumn{2}{|c|}{ residual MSW } \\
\hline & & $\begin{array}{c}\% \text { of } \\
\text { fraction }\end{array}$ & $\begin{array}{l}\% \text { of } \\
\text { total }\end{array}$ & $\begin{array}{c}\% \text { of } \\
\text { fraction }\end{array}$ & $\begin{array}{l}\% \text { of } \\
\text { total }\end{array}$ & $\begin{array}{c}\% \text { of } \\
\text { fraction }\end{array}$ & $\begin{array}{l}\% \text { of } \\
\text { total }\end{array}$ & $\begin{array}{c}\% \text { of } \\
\text { fraction }\end{array}$ & $\begin{array}{c}\% \text { of } \\
\text { total }\end{array}$ \\
\hline Fines & 10.07 & 0.00 & 0.00 & 100.00 & 10.07 & 0.00 & 0.00 & 100.00 & 10.07 \\
\hline Organic waste & 26.15 & 60.92 & 15.93 & 39.08 & 10.22 & 25.85 & 6.76 & 74.15 & 19.39 \\
\hline Paper & 14.96 & 50.39 & 7.54 & 49.61 & 7.42 & 50.39 & 7.54 & 49.61 & 7.42 \\
\hline Cardboard & 11.81 & 49.45 & 5.84 & 50.55 & 5.97 & 49.45 & 5.84 & 50.55 & 5.97 \\
\hline Coupled packaging & 1.16 & 0.00 & 0.00 & 100.00 & 1.16 & 0.00 & 0.00 & 100.00 & 1.16 \\
\hline Plastics & 10.46 & 10.89 & 1.14 & 89.11 & 9.32 & 10.89 & 1.14 & 89.11 & 9.32 \\
\hline Glass & 4.99 & 47.46 & 2.37 & 52.54 & 2.62 & 47.46 & 2.37 & 52.54 & 2.62 \\
\hline Metals & 2.28 & 53.88 & 1.23 & 46.12 & 1.05 & 53.88 & 1.23 & 46.12 & 1.05 \\
\hline Diapers & 2.07 & 0.00 & 0.00 & 100.00 & 2.07 & 0.00 & 0.00 & 100.00 & 2.07 \\
\hline Textiles & 4.14 & 60.00 & 2.48 & 40.00 & 1.65 & 60.00 & 2.48 & 40.00 & 1.65 \\
\hline Rubber & 1.08 & 17.21 & 0.19 & 82.79 & 0.89 & 17.21 & 0.19 & 82.79 & 0.89 \\
\hline Leather & 0.70 & 0.00 & 0.00 & 100.00 & 0.70 & 0.00 & 0.00 & 100.00 & 0.70 \\
\hline Const. and dem. waste & 4.62 & 80.00 & 3.69 & 20.00 & 0.92 & 80.00 & 3.69 & 20.00 & 0.92 \\
\hline Hazardous waste & 0.02 & 0.00 & 0.00 & 100.00 & 0.02 & 0.00 & 0.00 & 100.00 & 0.02 \\
\hline Wood & 1.77 & 60.00 & 1.06 & 40.00 & 0.71 & 60.00 & 1.06 & 40.00 & 0.71 \\
\hline Bulky material & 2.37 & 0.00 & 0.00 & 100.00 & 2.37 & 0.00 & 0.00 & 100.00 & 2.37 \\
\hline Other & 1.35 & 0.00 & 0.00 & 100.00 & 1.35 & 0.00 & 0.00 & 100.00 & 1.35 \\
\hline TOTAL & 100.00 & & 41.47 & & 58.53 & & 32.30 & & 67.70 \\
\hline
\end{tabular}


In Table 11, the main characteristics, in terms of amounts, LHV, HHV and obtainable thermal energy, of the material flows, defined in Paragraph 3, resulting from selection operations carried out on the residual commingled MSW generated in each analysed source separation scenario, are reported. By obtainable thermal energy, the quantity of releasable heat available for energy recovery is intended. This parameter may be used to identify the most interesting material flows for waste-to-energy conversion, since it accounts for both the amounts and LHV characteristics of the waste. In addition, it may be also employed to evaluate if the fractions destined to final disposal present potential for further energy recovery.

Figure 4 Material flows resulting from selection operations carried out in a typical MBT plant for each source separation scenario

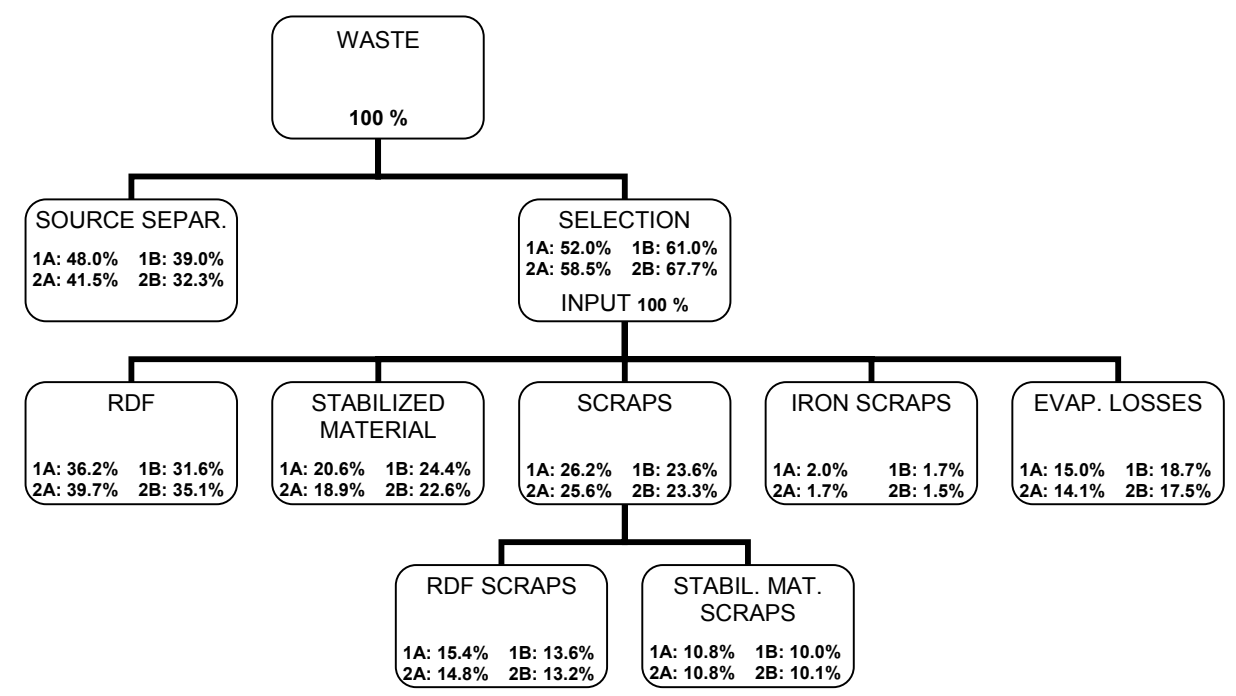

Analysing the results exhibited in Table 11, already the thermal characteristics of the commingled waste prove to be interesting, from the point of view of energy recovery (LHV between 10,990 and 12,450 kJ/kg) suggesting that direct incineration of this waste stream could be pursued, particularly for Scenarios $1 \mathrm{~A}$ and $2 \mathrm{~A}$, for which further material recovery appears to be costly and inefficient. All other technological options would entail a loss in recovered energy (see Table 10), as well as the lack of energy recovery from the scraps of the selection process. If all the commingled waste produced in Scenarios $1 \mathrm{~A}$ and 2A were incinerated, the final quantity of residual material (assumed as $25 \%$ of the processed amount of waste) would amount to 250,000 t/y. If instead the commingled waste were first separated to produce a fraction with a higher LHV (the RDF), a loss in thermal energy would result due to the missed energy recovery from the organic waste fraction (about $90 \mathrm{MW}$ ). Furthermore, the amounts of residual material to send to final disposal, including the stabilised organic fraction due to its poor qualitative characteristics, would roughly be double of those produced by direct incineration of the commingled waste, 497,000 t/y (Scenario 1A) and 554,000 t/y (Scenario 2A), assuming a production of residues from RDF combustion equal to $20 \%$ of the processed waste.

The second most interesting option, in view of maximising energy recovery and minimising residual material production, appears to be thermal treatment of biodried residual MSW, fraction type 2 in particular, since in this case separation of inert materials could allow for further material recovery and higher LHV. 
For Scenarios $1 \mathrm{~B}$ and $2 \mathrm{~B}$, owing to the superior quality of the collected organic waste, material recovery could be carried out for specific applications, such as environmental reclamation projects. Material selection could be preferred in this case, on the basis of the priority of material recovery compared to energy recovery, if the additional processing costs were accepted by the stakeholders. With this strategy, a considerable amount of material, corresponding to the organic fraction of the waste, could be recovered. The strategies for energy recovery from the residual fractions should be then established on the basis of the quantities and composition of the waste flows. In these scenarios, the best-suited fractions are RDF and the dry fraction. In particular, the dry fraction, type 2, appears to be the most interesting for energy recovery both for economic and environmental reasons, reducing the DOC of the waste to send to final disposal and presenting a higher energetic convenience. In this case, the final quantities of residual waste to be landfilled would amount to about half of those produced by direct incineration of the commingled waste, 120,000 t/y (Scenario 1B) and 140,000 t/y (Scenario 2B), assuming a production of combustion residues of the dry fraction - type 2 , equivalent to $20 \%$ of the processed waste. If only RDF were incinerated, 324,000 and 363,000 t/y of residues would be sent to landfilling in the two Scenarios $1 \mathrm{~B}$ and $2 \mathrm{~B}$, respectively.

Table 11 Summary of the energetic characteristics of the inflows and the products of different types of waste processing strategies aimed at energy recovery

\begin{tabular}{|c|c|c|c|c|c|}
\hline & & \multicolumn{4}{|c|}{ Scenario } \\
\hline & & $1 \mathrm{~A}$ & $1 B$ & $2 A$ & $2 B$ \\
\hline \multicolumn{6}{|l|}{ (1) Input waste } \\
\hline Quantities & $\mathrm{t} / \mathrm{y}$ & 921,105 & $1,084,850$ & $1,038,400$ & $1,201,100$ \\
\hline HHV & $\mathrm{kJ} / \mathrm{kg}$ & 14,000 & 12,700 & 14,200 & 12,950 \\
\hline LHV & $\mathrm{kJ} / \mathrm{kg}$ & 12,300 & 10,900 & 12,450 & 11,150 \\
\hline Obtainable thermal energy & MW & 397 & 415 & 453 & 470 \\
\hline \multicolumn{6}{|l|}{ (2) MBT-RDF flows } \\
\hline RDF - quantities & $\mathrm{t} / \mathrm{y}$ & 333,900 & 342,800 & 412,250 & 421,000 \\
\hline RDF - HHV & $\mathrm{kJ} / \mathrm{kg}$ & 21,000 & 20,600 & 20,350 & 20,050 \\
\hline RDF - LHV & $\mathrm{kJ} / \mathrm{kg}$ & 19,150 & 18,800 & 18,550 & 18,250 \\
\hline Obtainable thermal energy & MW & 224 & 226 & 268 & 269 \\
\hline RDF scraps - quantities & $\mathrm{t} / \mathrm{y}$ & 141,850 & 147,000 & 153,500 & 158,550 \\
\hline RDF scraps - HHV & $\mathrm{kJ} / \mathrm{kg}$ & 12,400 & 12,200 & 12,400 & 12,150 \\
\hline RDF scraps - LHV & $\mathrm{kJ} / \mathrm{kg}$ & 11,100 & 10,800 & 11,100 & 10,850 \\
\hline Obtainable thermal energy & MW & 55 & 56 & 60 & 60 \\
\hline Stabilised mat - quantities & $\mathrm{t} / \mathrm{y}$ & 189,300 & 265,246 & 196,250 & 272,050 \\
\hline Stab. scraps - quantities & $\mathrm{t} / \mathrm{y}$ & 99,000 & 108,500 & 111,850 & 122,500 \\
\hline Stab. scraps - HHV & $\mathrm{kJ} / \mathrm{kg}$ & 10,700 & 10,700 & 10,050 & 10,050 \\
\hline Stab. scraps - LHV & $\mathrm{kJ} / \mathrm{kg}$ & 9400 & 9300 & 8850 & 8800 \\
\hline Obtainable thermal energy & MW & 33 & 35 & 35 & 38 \\
\hline \multicolumn{6}{|l|}{ (3) Dry fraction - type 1} \\
\hline Dry fraction - quantities & $\mathrm{t} / \mathrm{y}$ & 475,750 & 363,400 & 432,600 & 441,050 \\
\hline Dry fraction - HHV & $\mathrm{kJ} / \mathrm{kg}$ & 18,400 & 24,367 & 23,793 & 23,506 \\
\hline Dry fraction - LHV & $\mathrm{kJ} / \mathrm{kg}$ & 16,750 & 22,103 & 21,616 & 21,321 \\
\hline Obtainable thermal energy & MW & 279 & 282 & 328 & 330 \\
\hline
\end{tabular}


Table 11 Summary of the energetic characteristics of the inflows and the products of different types of waste processing strategies aimed at energy recovery (continued)

\begin{tabular}{|c|c|c|c|c|c|}
\hline & & \multicolumn{4}{|c|}{ Scenario } \\
\hline & & $1 A$ & $1 B$ & $2 A$ & $2 B$ \\
\hline \multicolumn{6}{|l|}{ (4) Dry fraction - type 2} \\
\hline Dry fraction - quantities & $\mathrm{t} / \mathrm{y}$ & 574,750 & 598,300 & 677,600 & 702,050 \\
\hline Dry fraction - HHV & $\mathrm{kJ} / \mathrm{kg}$ & 17,103 & 16,741 & 16,849 & 16,521 \\
\hline Dry fraction - LHV & $\mathrm{kJ} / \mathrm{kg}$ & 15,484 & 15,112 & 15,261 & 14,930 \\
\hline Obtainable thermal energy & MW & 312 & 317 & 363 & 368 \\
\hline \multicolumn{6}{|l|}{ (5) Biodried fraction - type 1} \\
\hline Biodried fraction - quantities & $\mathrm{t} / \mathrm{y}$ & 498,745 & 571,174 & 561,982 & 663,908 \\
\hline Biodried fraction - HHV & $\mathrm{kJ} / \mathrm{kg}$ & 19,500 & 17,850 & 19,600 & 18,900 \\
\hline Biodried fraction - LHV & $\mathrm{kJ} / \mathrm{kg}$ & 17,900 & 16,300 & 18,000 & 17,300 \\
\hline Obtainable thermal energy & MW & 313 & 326 & 353 & 402 \\
\hline Inert fraction - quantities & $t / y$ & 109,184 & 133,979 & 123,362 & 140,829 \\
\hline \multicolumn{6}{|l|}{ (6) Biodried fraction-type 2} \\
\hline Biodried fraction - quantities & $t / y$ & 607,929 & 705,153 & 685,344 & 804,737 \\
\hline Biodried fraction - HHV & $\mathrm{kJ} / \mathrm{kg}$ & 16,000 & 14,500 & 15,600 & 15,600 \\
\hline Biodried fraction - LHV & $\mathrm{kJ} / \mathrm{kg}$ & 14,650 & 13,200 & 14,700 & 14,250 \\
\hline Obtainable thermal energy & MW & 313 & 326 & 353 & 402 \\
\hline
\end{tabular}

\section{Conclusions}

The general information derived from the analysis carried out in this study on the effects of different technological options on the quantities and composition of the material flows produced by MSW management practices, using data pertaining to the city of Rome, can be extended to other countries in which similar environmental policies and economical constraints exist.

Source separation of selected fractions of MSW is the main and indispensable strategy that allows to attain the goal of material recovery. Intercepting reusable materials, in fact, reduces both the amounts of waste to send to other forms of recovery and/or disposal, and the use of new resources and raw materials. Therefore, as long as it is technically and economically feasible, the objective of material recovery should be pursued at the costs that the community is willing to pay. However, as shown in this study, depending on the type of collection strategy adopted, source separation percentages cannot realistically exceed certain maximum percentages, particularly when they are addressed at selecting waste fractions that can be actually recycled. Hence, in order to abide to the EU waste management hierarchy, i.e. give priority to material recovery and recycling from waste, source separation of recyclable fractions from selected production activities should be preferred, instead of establishing increasingly higher (and impractical) overall source separation objectives.

Commingled residual MSW should be managed to pursue energy recovery and final safe disposal of all the waste streams that cannot be recycled. The material flows to be processed for energy recovery should be established on the basis of the composition of the waste, the actual environmental, technical and economical sustainability of the process, 
as well as the willingness to pay of the stakeholders. Direct incineration of the commingled waste could be acceptable in all the situations in which no further material recovery could be realistically pursued. When material recovery, for example of source-collected organic waste, is feasible, more refined management strategies could be pursued.

\section{References}

ANPA (National Agency for Environmental Protection) and ONR (National Observatory on Waste) (2001) Definizione di standard tecnici di igiene urbana, Manuali e linee guida 6/2001, ISBN 88-448-0048-9. (in Italian)

Burnley, S.J. (2007) 'The use of chemical composition data in waste management planning - a case study', Waste Management, Vol. 27, No. 3, pp.327-336.

Castaldi, M.J. and Themelis, N.J. (2010) 'The case for increasing the global capacity for waste to energy (WTE)', Waste and Biomass Valorization, Vol. 1, No. 1, pp.91-105.

CONAI (Italian National Packaging Waste Consortium) (2008) Riciclo e recupero dei materiali di imballaggio:risultati 2007 e nuove prospettive. (in Italian)

Cossu, R. (2009) 'Driving forces in national waste management strategies', Waste Management, Vol. 29, pp.2797-2798.

De Stefanis, P., Iaboni, V. and Caggiano, R. (2009) 'Rapporto sul recupero energetico da rifiuti urbani in Italia, seconda edizione', FederAmbiente and ENEA ed. (in Italian). Available online at: http://www.enea.it/produzione_scientifica/volumi/V2009_06RapportoRecuperoRifiuti.html

European Council (1975) 'Council Directive 75/442/EEC of 15 July 1975 on waste', Official Journal of the European Communities, 25 July 1975, L 194, p.39.

European Council (1999) 'Council Directive 99/38/EEC of 26 April 1999 on the landfill of waste', Official Journal of the European Communities, 16 July 1999, L 182.

European Council (2003) 'Council Decision of 19 December 2002 establishing criteria and procedures for the acceptance of waste at landfills pursuant to Article 16 of and Annex II to Directive 1999/31/EC', Official Journal of the European Communities, 16 January 2003, L 11 .

European Council (2008) 'Council Directive 2008/98/EEC of 19 November 2008 on waste and repealing certain Directives', Official Journal of the European Communities, 22 November 2008, L 321.

Eurostat (2009) Statistics in focus: generation and treatment of waste. Available online at: http://epp. eurostat.ec.europa.eu/cache/ITY_OFFPUB/KS-SF-09-030/EN/KS-SF-09-030-EN.PDF

ISPRA (Italian Superior Institute for Environmental Protection and Research) (2008) Rapporto Rifiuti 2008 (in Italian). Available online at: http://www.apat.gov.it/site/it-IT/APAT/Pubblicazioni/ Rapporto_rifiuti/Documento/rapporto_rfi08.html

Italian Parliament (2003) 'Decreto Legislativo 13 gennaio 2003, n. 36, Attuazione della direttiva 1999/31/CE relativa alle discariche di rifiuti', Gazzetta Ufficiale, 12 March 2003, Vol. 59. (in Italian)

Italian Parliament (2006) 'Decreto Legislativo 3 aprile 2006, n. 152, Norme in materia ambientale', Gazzetta Ufficiale, 14 April 2006, Vol. 88. (in Italian)

Koufodimos, G. and Samaras, Z. (2002) 'Waste management options in southern Europe using field and experimental data', Waste Management, Vol. 22, No. 1, pp.47-59.

Lombardi, F. and Muraro, P. (2007) 'I rifiuti prodotti in ambito urbano e le frazioni ricavabili per la valorizzazione energetica', Nuova Gea Quaderni per l'Ambiente: Energia da Rifiuti. Tecniche di valorizzazione ed Utilizzazione, Vol. 2, pp.11-42. (in Italian)

Magrinho, A. and Semiao, V. (2008) 'Estimation of residual MSW heating value as a function of waste component recycling', Waste Management, Vol. 28, No. 12, pp.2675-2683. 
Minciardi, R., Paolucci, M., Robba, M. and Sacile, R. (2008) 'Multi-objective optimization of solid waste flows: environmentally sustainable strategies for municipalities', Waste Management, Vol. 28, No. 11, pp.2202-2212.

Morrissey, A.J. and Browne, J. (2004) 'Waste management models and their application to sustainable waste management', Waste Management, Vol. 24, No. 3, pp.297-308.

Nyland, C.A., Modahl, I.S., Raadal, H.L. and Hanssen, O.J. (2003) 'Application of LCA as a decision-making tool for waste management systems', International Journal of Life Cycle Assessment, Vol. 8, No. 6, pp.331-336.

OECD (Organization for Economic Co-operation and Development) (2008) Environmental Data Compendium 2006-2008 on Waste. Available online at: http://www.oecd.org/dataoecd/ 22/58/41878186.pdf

Porteous, A. (2005) 'Why energy from waste incineration is an essential component of environmentally responsible waste management', Waste Management, Vol. 25, No. 4, pp.451-459.

Salhofer, S., Obersteiner, G., Schneider, F. and Lebersorger, S. (2008) 'Potentials for the prevention of municipal solid waste', Waste Management, Vol. 28, No. 2, pp.245-259.

Tchobanoglous, G., Theisen, H. and Vigil, S. (1993) Integrated Solid Waste Management, McGraw-Hill, New York.

United Nations (UN) (2009) The Millennium Development Goals Report 2009. Available online at: http://www.un.org/millenniumgoals/pdf/MDG_Report_2009_ENG.pdf

Vehlow, J., Bergfeldt, B., Visser, R. and Wilén, C. (2007) 'European Union waste management strategy and the importance of biogenic waste', Journal of Material Cycles and Waste Management, Vol. 9, No. 2, pp.130-139.

Velis, C.A., Longhurst, P.J., Drew, G.H., Smith, R. and Pollard, S.J.T. (2009) 'Biodrying for mechanical-biological treatment of wastes: a review of process science and engineering', Bioresourse Technology, Vol. 100, No. 11, pp.2747-2761.

Winkler, J. and Bilitewski, B. (2007) 'Comparative evaluation of life cycle assessment models for solid waste management’, Waste Management, Vol. 27, No. 8, pp.1021-1031. 